\title{
A ECOLOGIA LINGUÍSTICA NAS PLACAS E ANÚNCIOS POPULARES
}

\section{(The linguistic ecology in popular announcements)}

\author{
Altair Martins Gomes ${ }^{1}$ \\ (Universidade de Brasília - UnB)
}

\begin{abstract}
By language man is constituted as social subject and, therefore, cultural. Given the importance of writing for the literate civilizations, it's necessary to study spoken language interfacing with written language in order to realize how these discoursive instances appear as interactional practices and subjacent cultural issues. The oral language modality phenomena of Brazilian Portuguese are present in signs and popular advertisements. In this type of writing, the ecology of languages reveals itself in phoneticphonological and morphological properties of grammar, revealing many phenomena for research. The research objective was a reflection on the written version of oral language from a 'language ecology' perspective. The ability to use linguistic variants, to go from one code or style to another, to select phonetic variants and appropriate prosodic patterns are part of communicative competence that speakers produce although these resources are in disagreement with standard language and are negatively evaluated by society.
\end{abstract}

Keywords: ecology languages, contact, orality and literacy, Ecolinguistics.

\section{RESUMO}

Pela linguagem o homem se constitui como sujeito social e, portanto, cultural. Dada a importância da escrita para as civilizações letradas, necessário é o estudo da interface língua falada versus escrita para percebermos como estas instâncias discursivas se relacionam como práticas interacionais e as questões culturais aí subjacentes.

1. Mestre em Linguística pela Universidade de Brasília, onde cursa atualmente Doutorado junto ao Programa de Pós-Graduação em Linguística, sob a orientação do Prof. Dr. Hildo Couto. 
Os fenômenos da modalidade oralizada do português do Brasil se mostram presentes nas placas e anúncios populares. Nesse tipo de escrita, a ecologia linguística se revela nas propriedades fonéticofonológica e morfológica da gramática e revela muitos fenômenos para investigação. O objetivo da pesquisa foi a reflexão sobre a escrita oralizada do Português do Brasil sob o viés da ecologia linguística, fazendo algumas reflexões sobre as hipóteses sobre a escrita com base na forma oral/prosódica. Isso quer dizer que a habilidade de utilizar variantes linguísticas, de transitar de um código ou estilo para outro, de selecionar variantes fonéticas e padrões prosódicos apropriados fazem parte da competência comunicativa que os falantes elaboram de acordo com as diversas apropriações que fazem dos códigos linguísticos, ainda que tais recursos estejam em desacordo com a norma padrão e sejam socialmente avaliados pejorativamente.

Palavras-chave: ecologia do contato de linguas, oralidade e escrita, ecolinguística.

\section{Introdução}

O presente artigo tem como objetivo trazer à luz das discussões as reflexões sobre as marcas da oralidade na escrita das placas e anúncios populares, a partir de fenômenos fonológicos da fala muito presentes em escreventes que ainda não dominam as convenções ortográficas. A perspectiva adotada é a da ecologia linguística (Couto, 1996, 2007, 2009) e da sociolinguística (Bortoni-Ricardo, 2004, 2005), além da perspectiva ecossistêmica ${ }^{2}$ vista nas discussões sobre as variedades do português brasileiro, na extensa literatura sociolinguística, em especial na abordagem sobre a heterogeneidade do português brasileiro e o ensino de língua materna. Na diversidade do português do Brasil em

2. Embora os autores da Sociolinguística não se refiram diretamente às relações entre língua e o meio ambiente, entendo que todo o estudo analítico dessa área da linguística faz uma intensa relação entre meio ambiente, língua e povo, de modo que a língua e a sociedade são intimamente ligados e não se dissociam. O ecossistema não é apenas um aspecto biológico, mas social, antropológico, cultural e possui uma dimensão mais ampla do que apenas a relação especial entre a biologia das espécies e o meio ambiente. 
Mollica (1998, 2007), Perini (2010); Bagno (2003) e nos estudos sobre redes de interações sociais discutidas em Milroy \& Margrain (1980) e Milroy 1980).

As reflexões, em um primeiro momento, foram espontâneas e ocorreram em minhas aulas de filosofia sobre os conceitos de língua, povo e território, de acordo com a abordagem ecolinguística vista em Couto $(2007,2009)$. Segundo esse autor, para que haja uma língua é necessário que haja um povo que a use, de modo que dessa relação ocorra uma simbiose povo-território intimamente interligada. O linguista também afirma que as línguas tendem a se diversificar, primeiro dialetalmente e, em seguida, na direção do plurilinguismo, cujo processo de transformação é paralelo ao da diversificação biológica. ${ }^{3}$ Couto salienta que no movimento que leva à diversificação linguística, à migração dos povos, há também a influência de uma língua sobre a outra. Nesse sentido, podemos dizer que os dialetos em interação também se sobressaem uns sobre os outros.

Provoquei os meus alunos com algumas questões sobre quais variedades linguísticas poderiam ser percebidas no ambiente, quais estavam se dispersando ou focalizando e se a língua era também um elemento do ecossistema ou era algo fora dele. Como vimos em Couto (2007), o ecossistema vai além de objeto de interesse da biologia, como o estudo da natureza e suas relações com as espécies, a fauna, a flora e o homem, mas como algo maior, sistêmico, onde todos os elementos se relacionam em uma grande rede de interação. Daí dizermos que a linguagem se torna um fio de tessitura que liga o homem a tudo que o cerca, ao seu meio ambiente e revela-se em forma discursiva escrita e oral pelos diversos gêneros discursivos.

Após a inclusão das questões trazidas pela Ecolinguística para sala de aula, os alunos começaram a descrever os modos de constituição da escrita, seus diversos gêneros e as diferenças da modalidade oral. Falaram também sobre o conceito de linguagem e a importância da escrita para as sociedades letradas. Refletiram sobre a consciência

3. O autor compara a evolução linguística à das espécies, cuja transformação ao longo de um determinado lapso de tempo é algo natural e inevitável. 
ecolinguística ${ }^{4}$ que a situa no tempo e no espaço, a partir dos usos e escolhas linguísticas que fazem em determinadas situações da vida. Tendo em vista essa série de questões, fomos a campo procurar nos arredores de Brasília, em uma Cidade Satélite do Distrito Federal chamada Ceilândia, as placas e anúncios populares que tivessem em sua escrita as formas de constituição de uso diferentes daquelas preconizadas pela gramática tradicional.

Durante todo o ano de 2011, meus alunos e eu fomos colecionando os fenômenos encontrados nesses veículos de comunicação e é o resultado desse trabalho de observação, anotação e discussões que redundaram no material para as minhas reflexões sobre as hipóteses de escrita do povo, justificadas na base da fonologia da língua. Mas antes de ir à discussão sobre a grafia dos anúncios populares, veremos aqui algumas questões necessárias ao conceito de língua, segundo a visão da ecologia linguística e as implicações daí decorrentes. Por que anúncios e placas populares? Porque eles estão inseridos no ecossistema da língua, produzem efeito sobre as pessoas e a natureza, seja pela informação aí prestada, seja pelo modo como eles foram constituídos, as reflexões sobre os modos de constituição da escrita, os processos de construção da modalidade escrita/oralidade aí subjacentes, e pela poluição visual que eles podem provocar. Desse modo, buscamos na abordagem ecolinguística o norte da nossa pesquisa. O uso da linguagem e como a utilizamos para fazer o registro de nossa história para a posteridade são formas que nos distinguem das outras espécies.

Pela linguagem o homem se constitui como sujeito social e se revela como um ser eminentemente cultural. Por sua importância para as civilizações, necessário é o estudo da interface linguagem falada (oralidade) e linguagem escrita, a fim de percebermos como estas instâncias discursivas se relacionam ou não como práticas interacionais

4. Segundo Couto (2007:39), a Ecolinguística é o estudo das relações entre língua e meio ambiente, de modo a relacionar a linguística à ecologia, desenvolvendo assim, a consciência crítica em relação ao uso da língua, em que o homem se situa pela linguagem, como parte integrante do ecossistema em determinado espaço, tempo, situação e o meio ambiente. 
e como a cultura está inserida nessas práticas. Nesse contexto, a palavra falada mantém unidos os laços familiares e a predominância dos valores sociais fortalecida por seu estatuto de verdade absoluta, daí Marcuschi (2001: 48) afirmar que a oralidade confunde-se com a própria história do homem. Por outro lado, a palavra escrita é bem posterior ao surgimento da oralidade, tendo surgido no Ocidente com o advento do alfabeto fonético, provavelmente no século XVI a.C. Uma das funções da linguagem escrita é guardar na memória os saberes e os bens culturais construídos na história do homem.

Dada a importância da língua escrita para a cultura ocidental no Séc XXI, é mister estudar as influências da oralidade sobre ela, em especial, quando essas duas modalidades de interação são intensamente utilizadas em maior ou menor proporção pela escola. Por sua vez, o estudo das redações escolares nos possibilita observar o quanto as características do discurso oral estão ou não presentes nos textos, apesar de a escola ter a crença nas dicotomias polarizadas e estanques entre a comunicação verbal escrita e a oral (Marcuschi, 2001: 31). Sob o viés da ecologia linguística, o estudo do gênero escrita permitir-nos-ia, em princípio, afirmar que a palavra falada se distingue da escrita por vários fatores, entre eles, aspectos discursivos da pragmática no momento da enunciação, cabendo aí determinadas escolhas lexicais e estilísticas, enquanto a outra exigiria uma maior obediência às normas prescritivistas estabelecidas por um padrão gramatical (gramática tradicional), cabendo à modalidade língua escrita o espaço para o uso da norma culta e a prescrição da ortografia a fim de eliminar os aspectos fonético-fonológicos que interferem no aprendizado da escrita. A experiência como professor me permitiu fazer muitas asserções sobre a linguagem, em especial, sobre a influência de alguns fenômenos da fala sobre a escrita.

\section{Aspectos metodológicos}

No panorama das instituições de ensino brasileiras, a aquisição da língua escrita é o grande desafio para educadores e educandos. 
De forma espantosa, a realidade escolar (FARACO, 2007; 1997) tem revelado que um surpreendente contingente de alunos está excluído da escola, no início mesmo da alfabetização, por apresentarem resultados insuficientes no domínio de algumas habilidades letradas, em especial, a leitura e a escrita.

Entretanto, raras vezes se tem questionado as metodologias empregadas pelo professorado, deixando, desse modo, de analisar as condições em que o indivíduo é conduzido à aquisição da modalidade escrita da língua. Muitas dessas metodologias não são alicerçadas nas contribuições epistemológicas da linguística, o que contribui para a não compreensão da realidade linguística e, por conseguinte, de modelos e paradigmas que seriam muito úteis para uma pedagogia culturalmente sensível (Erickson, 1987) e para um modelo de letramento funcional (Barton, 1994).

Marcuschi (2001: 17) frisa que a escrita se tornou indispensável na história do homem, ou seja, sua prática e avaliação social a elevaram a um status mais alto, chegando a simbolizar educação, desenvolvimento e poder. Portanto, pensar sobre as práticas da escrita, ensino e seus modos heterogêneos de constituição em correlação à linguagem falada é necessário, dada a importância dessas instâncias discursivas em uma sociedade letrada como a do Distrito Federal. Como já foi dito anteriormente, o enfoque do nosso trabalho foram as reflexões dadas pelas relações do homem com a língua, e o registro dessa relação em anúncios deixados no meio ambiente. A tríade povo, língua e território proposta por Couto (2007) nos favoreceu a reflexão sobre como esse povo usa a língua escrita, como ele concebe a escrita em suas formas não escolarizadas e produz material para se relacionar com o outro, por isso, o presente trabalho se propõe a analisar anúncios feitos pelo povo, cuja escrita revela poucos anos de escolarização.

A coleta de dados foi feita a partir de fotos tiradas de anúncios, anotações em cadernetas e a observação desses materiais retirados das ruas na Feira Central de Ceilândia, no Shopping Popular, na região do centro dessa cidade, no Bairro Expansão do Setor O, na Feira do Rolo, no Setor Habitacional Sol Nascente e no Setor Por do Sol. Registre-se que todos esses lugares, à exceção do centro de 
Ceilândia, da Feira Central e Shopping Popular, são de periferia, ou melhor, se essa cidade já é bastante periférica em relação ao Plano Piloto (Brasília propriamente dita), os dados colhidos foram retirados da periferia da periferia, onde se concentra um grande contingente de pessoas com baixa escolaridade e pertencentes às classes econômicas menos favorecidas, sem maiores acessos aos meios culturais disponibilizados pelo capital simbólico da humanidade. Há de se esclarecer que nessas comunidades não há teatro, cinema, espaços para lazer, para manifestações artísticas e onde falta lugar para preservação e compartilhamento de cultura, sobram violência, falta de saneamento e lazer. Também não se sabe a origem desses escreventes, mas os dados disponibilizados pelo CENSO 2010 revelam que Ceilândia tem sua história marcada pela migração de nordestinos, o que a torna a cidade mais nordestina do Planalto Central, portanto, rica de valores e da cultura típica desses estados.

No dizer de Lopes (2006: 15), na nossa sociedade, o uso da escrita penetrou com muito vigor, estabelecendo-se como um recurso que permeia uma parte considerável das interações sociais, além de haver adquirido prestígio por força de fatores de diversas ordens, como a natureza social, histórica e cultural, o que nos permite afirmar que a escrita não deve ser considerada apenas como uma modalidade de uso da língua, mas uma espécie de evento discursivo que manifesta diversidade linguística. $\mathrm{O}$ estudo da relação oral/escrito está inserido nos estudos de letramento, concebido aqui como um conjunto de práticas sociais culturalmente constituídas e socialmente situadas (Marcuschi, 2001: 32; Lopes, 2006: 16). A dimensão ecossistêmica da linguagem que usamos é holística e nos faz ver a língua do ponto de vista geral e global, conforme os ensinos de Couto (2007) e Haugen (1972).

É um hábito na cultura escolar a crença de que esses dois modos de expressão e comunicação (oral e escrito) são estanques, dicotômicos e desassociados. Essa percepção da escola, por sua vez, gera uma pedagogia pouco afeita à heterogeneidade, às diferenças e às causas e efeitos das atitudes dos alunos em preservar nas 
dissertações, as características e especificidades da oralidade. O nosso estudo é no sentido de analisar os fenômenos da escrita oralizada; entender a multiplicidade da linguagem e a diversidade da cultura da sociedade em que estamos imersos, de alguma forma, a fim de esclarecer porque muitos fatos estão presentes nas práticas textuais sociais. Minha abordagem segue a visão ecolinguística, como alguém que enxerga o ambiente de cima para baixo, da parte mais geral para o particular. Assim, vemos os anúncios populares contextualizados, como alguém que vê a casa (ecossistema) e vai se aproximando para ver mais de perto as paredes, as janelas, o piso, do que são constituídos, os alicerces, a constituição de cada coisa e selecionando mais ainda cada detalhe a fim de estabelecer relações micro e macrossistêmicas com a casa inteira. Na linguagem, a mesma metáfora da casa: para ver cada placa de anúncios, foi preciso entender a linguagem em seu aspecto fonético-fonológico e no morfossintático das palavras utilizadas e das sentenças e, enfim, para entender os processos de concepção da escrita dos escreventes. Do ponto de vista da ecolinguística, o estudo da gramática sob o viés da endoecologia da língua. ${ }^{5}$

Devo esclarecer que pensar sobre as diferenças e similaridades entre oralidade e escrita não é a única tarefa para este trabalho, porque reflito também sobre problemas de educação brasileira, sobre questões sociolinguísticas da linguagem subjacentes à heterogeneidade do português brasileiro e ao ensino de língua materna. Minha discussão se aprofunda em torno de alguns fenômenos relativos à ortografia, em particular quando há supressão de letras, muito presente na oralidade quando se fala muito rápido.

5. A Endoecologia, segundo Couto (2007:152) é o estudo da Ecologia interna aos organismos, ou seja, são as relações que se verificam internamente na língua, na sua endoecologia, conforme proposta de Makkai (1993). Portanto, o estudo das partes da gramática nos possibilita essa visa endoecológica, haja vista que a gramática faz parte da estrutura interna da língua, e, portanto, pode ser abordada pela perspectiva ecológica, ou seja, do ecossistema e todos os conceitos que the são inerentes. 


\section{Análise dos dados}

No ensino de língua materna, trabalhar com a perspectiva ecolinguística e os anúncios populares constitui um constitui um bom ponto de partida para o ensino de língua, haja vista a riqueza de constituições de escrita muito diversas daquelas preconizadas pela norma padrão. Quando os alunos percebem essas diferenças, umas gritantes, outras nem tanto, o professor pode desenvolver uma prática de percepção sobre os desvios da norma padrão, o que garante a reflexão, por parte dos alunos, sobre os motivos que levam alguém a omitir sílabas e letras em sua produção gráfica em função dos padrões fonológicos utilizados em sua fala. Podemos afirmar que a omissão de letras decorre de uma série de fatores relacionados à pronúncia das palavras e ao tratamento pedagógico dado pela escola a este fenômeno. Destaco alguns fatores:

1. A correspondência sonora parcial entre a variedade linguística empregada pelo usuário com o registro de prestígio social é uma das causas da omissão de letras ou monotongação, quando na escrita ditada pela gramática normativa há ditongos. Em certas áreas rurais, mas não só, os usuários da língua portuguesa não usam certos ditongos. No lugar de banheiro, falou, tesouro, ocorre a supressão da última vogal que compõe o ditongo (banhero, falô, tesoro). Evidenciam-se, também, outros dois fenômenos: a supressão das sílabas pretônicas como no caso das palavras: está, espera e você (tá, pera, cê) e a eliminação do "d" nos verbos que se apresentam no gerúndio tais como cantando, falando e amando (cantanu, falanu, amanu). Como o falante ainda não estabeleceu uma distinção clara entre o discurso oral e o discurso escrito, acaba por suprimir sílabas em sua representação gráfica.

2. O desconhecimento do uso de algumas letras, em certos contextos gráficos, pode levar o aluno a suprimir determinados elementos gráficos. Tal fenômeno acontece no uso dos encontros consonantais gr, br, vr, tr, gl, bl, tl. Grafa-se, com supressão de letras, bincar, livo, gande, panta no lugar de brincar, livro, grande e planta.

3. Não se usa o 'r' em verbos escritos no infinitivo. Tal fenômeno pode levar à transcrição das palavras cantar, amar e levar como cantá, 
amá e leva. O mesmo acontece com o uso do "s" como marca de plural. Na frase "As canetas amarelas estão nas mesas", encontram-se registros do tipo: As caneta amarela estão nas mesa.

De acordo com pesquisas realizadas por Zorzi (2003:52), os índices de omissão de letras na produção de textos dos alunos das séries iniciais estão relacionados aos métodos de alfabetizadores que costumam trabalhar com um padrão de escrita determinado por uma sequência $\mathrm{C}$ (consoante) $\mathrm{V}$ (vogal). Observa-se, no esquema alfabetizador tradicional, uma forte tendência de expor palavras regidas por um padrão ordenado em consoantes e vogais de forma alternada.

$$
\begin{aligned}
& \text { Ex: A bo ne ca é } \quad \text { bo ni ta. } \\
& \text { C CVCVCV V }
\end{aligned}
$$

O padrão silábico $(\mathrm{CV})$ pode levar os alunos a se habituarem a escrever sob uma orientação simplificadora do sistema de escrita. Dessa forma, institui-se a crença de que todas as palavras se estruturariam de uma única forma. Seguindo esse raciocínio, é possível afirmar que a supressão de letras, na escrita das crianças, tem a ver com a concepção de ensino que parte da exposição de sílabas simples para, mais tarde, apresentar as complexas. Aos olhos do autor, essa perspectiva parece ser algo danoso.

De acordo com Zorzi (2003:56), as omissões gráficas não são aleatórias. Cabe ao professor observar a lógica estabelecida para o aluno grafar as palavras. É muito importante que o professor reflita sobre os princípios que direcionam a sua prática pedagógica.

Chamamos atenção para alguns casos de omissão de letras que podem estar relacionados à falta de sincronia entre o ato de pensar uma palavra e grafá-la no momento seguinte. Nesse sentido, os meus alunos que menos tiveram contanto estrito com práticas letradas, segundo os próprios relatos, não haviam desenvolvido procedimentos de controle sobre a sua produção gráfica. Por isso, a importância de se estimular o hábito de o aluno revisar os textos no ato de sua 
produção. O meu auxílio como professor na atividade de revisão foi de suma importância, visto que os alunos se sentiram mais seguros e mantiveram uma postura reflexiva diante das solicitações propostas pelo pesquisador.

A grande maioria dos casos de acréscimo indevido de letras tem forte vinculação com o mecanismo de hipercorreção. Tal fenômeno ocorre quando o indivíduo tem certa consciência dos condicionamentos ortográficos, mas ainda não sabe usá-los adequadamente. Sendo assim, a transgressão de uma norma é decorrente de uma generalização indevida no plano da fala e/ou no plano da escrita. No plano da escrita, exemplificamos um caso de hipercorreção narrando a situação do sujeito que viu escrito em algum lugar as formas gráficas "há" e "espécie". Sendo assim escreve um bilhete para a sua namorada: "Vou há festa na casa de Rodrigo, por favor, não me esperie". Muitos casos de hipercorreção (associados ao acréscimo de letras) são decorrentes de uma correção exagerada por parte do professor. Quando o professor censura o aluno dizendo Não se fala tesora, se fala tesouura sem discutir a questão, ele abre brecha para uma assimilação mecânica. $\mathrm{O}$ aluno memoriza as afirmações e transfere esse saber superficial para outras situações, escrevendo professoura, espeira, carinhio.

Constato que as dificuldades ortográficas podem ser decorrentes de diversos fatores. Cabe ao professor acompanhar o processo de apropriação da escrita desenvolvido pelo aluno, auxiliando na compreensão das arbitrariedades que se encontram no sistema ortográfico. Um dos caminhos que pode ajudar o aluno a compreender melhor as convenções gráficas, é leva-lo a perceber as regularidades e irregularidades que existem em nosso sistema de escrita. Como ele é assim constituído, torna-se necessário desenvolver dois tipos de atividades: uma voltada para a percepção de aspectos regulares da escrita e outra voltada para o domínio mnemônico do saber ortográfico. Nesse sentido, toda situação de escrita pode ser um momento de reflexão em que o aluno possa exprimir suas hipóteses de como grafar as palavras. Para que o escrevente, quando aluno, obedeça as normas prescritivas, é necessária a consulta a fontes confiáveis nas quais ele possa tirar suas dúvidas. O jornal, o dicionário e o saber 
ortográfico aprendido do professor, geralmente, são as principais fontes de consulta de que o aluno lança mão para maior esclarecimento no campo da ortografia.

Ainda que tenha um forte apelo à memória, a aprendizagem da ortografia não é um processo passivo: trata-se de uma construção individual, para a qual a intervenção pedagógica tem muito a contribuir. Para o sucesso na aprendizagem em sala de aula, é importante que as estratégias didáticas para o ensino da ortografia se articulem em torno de dois eixos básicos: 1) da distinção entre o que é 'produtivo' e o que é 'reprodutivo' na notação da ortografia da língua, permitindo no primeiro caso o descobrimento explícito de regras geradoras de notações corretas e, quando não, a consciência de que não há regras que justifiquem as formas corretas fixadas pela norma; 2) da distinção entre palavras de uso frequente e infrequente na linguagem escrita impressa.

Os casos em que as regras existem podem ser descritos como produzidos por princípios geradores 'biunívocos', 'contextuais' e 'morfológicos'. O princípio gerador biunívoco é o próprio sistema alfabético nas correspondências em que a cada grafema corresponde apenas um fonema e vice-versa. As regras do tipo contextual (ex.: o uso de RR, QU, GU, NH, M/N antes de consoante, etc.) são aquelas em que, apesar de se encontrar no sistema alfabético mais de um grafema para notar o mesmo fonema, a norma restringe os usos daqueles grafemas formulando regras que se aplicam parcial ou universalmente aos contextos em que são usados. Por fim, as regras do tipo morfológico são as que remetem aos aspectos morfológicos e à categoria gramatical da palavra para poder decidir sua forma ortográfica (ex.: anda $(\mathrm{r})$, pensa(r): verbos no infinitivo; fize (ss) e, ouvi(ss)e: imperfeito do subjuntivo; portuguesa(s)a, ingle(s)a: adjetivos gentílicos terminados em /eza/; rique(z)a, pobre(z)a: substantivos terminados em /eza/, etc.).

A posição que defendo é a de que, independentemente de serem regulares ou irregulares - definidas por regras ou não, as formas ortográficas mais frequentes na escrita devem ser aprendidas o quanto antes. Não se trata de definir rigidamente um conjunto de palavras a 
ensinar e desconsiderar todas as outras, mas de tratar diferentemente, por exemplo, a escrita inadequada de 'quando' e de 'questiúncula', de 'hoje' e de 'homilia' - dada a enorme diferenciação na frequência de uso de umas e outras. É preciso que se diferencie o que deve estar automatizado o mais cedo possível para liberar a atenção do aluno para outros aspectos da escrita e o que pode ser objeto de consulta ao dicionário. Esta pressupõe conhecimento sobre as convenções da escrita e sobre as do próprio portador: além de saber que as palavras estão organizadas segundo a ordem alfabética (não só das letras iniciais, mas também das seguintes), é preciso saber, por exemplo, que os verbos não aparecem flexionados, que o significado da palavra procurada é um critério para verificar se determinada escrita se refere realmente a ela, etc. Assim, o manejo do dicionário precisa ser orientado, pois requer a aprendizagem de procedimentos bastante complexos.

O trabalho com a normatização ortográfica deve estar contextualizado, basicamente, em situações em que os alunos tenham razões para escrever corretamente, em que a legibilidade seja fundamental porque existem leitores de fato para a escrita que produzem. Deve estar voltado para o desenvolvimento de uma atitude crítica em relação à própria escrita, ou seja, de preocupação com a adequação e correção dos textos. No entanto, diferentemente de outros aspectos da notação escrita - como a pontuação -, as restrições da norma ortográfica estão definidas basicamente no nível da palavra. Isso faz com que o ensino da ortografia possa desenvolver-se por meio tanto de atividades que tenham o texto como fonte de reflexão como de atividades que tenham palavras não necessariamente vinculadas a um texto específico (Brasil, 1997:36).

Como foi dito anteriormente, na perspectiva da endoecologia da língua, não é a análise prescritiva do certo e errado das formas de escrever nem o julgamento pejorativo que se faz sobre as escritas selecionadas pela pesquisa. O que nos interessa é a relação holística entre as escolhas desses escreventes e suas hipóteses com apoio da oralidade. Segundo Couto (2007), a gramática, por ser constituída de regras, tem a ver com inter-relações existentes na natureza, de modo que 
sintaxe, morfologia, léxico e fonologia são apenas aspectos diferentes de uma mesma realidade, que é a endoecologia da língua. Em primeiro momento, como afirma o autor, devemos separar operatoriamente essas partes para serem analisadas microscopicamente, porém, não se pode deixar de esquecer que cada uma delas faz parte de uma imensa teia de inter-relações, que por sua vez, relacionam-se com o ensino de língua materna e as reflexões paralelas às reflexões sobre o desempenho dos escreventes contextualmente situados no ecossistema, na natureza, nas práticas sociais comuns aos grupos urbanos.

Sobre a análise dos fenômenos gramaticais, a visão da ecologia interna de uma língua possibilita o reconhecimento da relação que as partes têm com o todo. Desse modo, quando refletimos a influência da oralidade sobre a escrita, não estamos apenas realizando uma aplicação da gramática tradicional sobre o sistema de regras da fala, mas querendo entender, do ponto de vista holístico e do ecossistema, como um sistema da língua apoia-se no outro ou eles se relacionam entre si quando não se tem domínio da norma escrita. Uma análise isolada, sem a visão ecossistêmica, uma escrita discordante da norma será julgada como erro e isso tem diversas implicações. Bortoni-Ricardo (2005: 79) considera pedagogicamente incorreta a incidência do erro sobre o educando, uma vez que isso pode gerar atitude de humilhação e que, ao contrário disso, uma pedagogia que é culturalmente sensível aos saberes dos educandos está atenta às diferenças entre a cultura que eles representam e a escola, e mostra ao professor como encontrar formas efetivas de conscientizar os educandos sobre as diferenças. Embora a autora não faça nenhuma referência à ecolinguística, a análise que ela faz sobre as hipóteses que os alunos/escreventes teriam sobre a escrita, sobre erros, as diferenças dialetais, culturais e a heterogeneidade da língua vem ao encontro da visão ecolinguística, como um dos elementos do ecossistema, e pode ser analisada com vários olhares sistêmicos e dinâmicos (Couto, 2007).

Sobre a ortografia, Bagno (2003: 123) declara que a ortografia oficial é fruto de um gesto político, determinado por decreto; é resultado de negociações e pressões de toda ordem, quer geopolíticas e econômica, quer sejam ideológicas. A abordagem do conceito de erro, 
a meu ver, deve ser analisada com maior atenção, pois como afirma Possenti (1996:81), a definição de erro é um problema complexo, pois vai além de ser apenas uma questão gramatical da língua escrita. Segundo esse autor, os erros que condenamos só são erros se o critério de avaliação for externo à língua ou ao dileto, ou seja, se o critério for social, portanto, depende do ponto de vista do avaliador.

Para Bagno (2003: 91), pedagogicamente correto seria substituir o termo "erro" por "tentativa de acerto", por ser a língua escrita nada mais do que uma tentativa de representar a língua oral, construída de acordo com características sociolinguísticas. A língua escrita não é uma extensão da língua oral, por ter cada uma traços específicos que as demarcam e possuem traços gerais que as aproximam. Porém, em ambas as modalidades discursivas a presença de características sociolinguísticas se mostra de modo recorrente, por isso, quando o professor trata essas duas instâncias discursivas como modalidades dicotômicas e estanques, a visão que sobressai é sempre a de que a língua escrita é superior à língua falada e que esta deve seguir os ditames daquela, o que gera uma visão distorcida da realidade.

Dentro do contexto da análise da língua em seu aspecto relacional com o meio ambiente e ecologia linguística, as interferências da oralidade na escrita, como pondera Bortoni-Ricardo (2004) ${ }^{6}$, apontam para o fato de que há uma diferença crucial no tratamento pedagógico de erros na produção oral dos alunos. A autora argumenta que a sociolinguística considera os primeiros como alternativas associadas a variantes e estilos, e o segundo, resultado de hipótese mal sucedida na aprendizagem da tecnologia da escrita, donde a necessidade de o erro ortográfico precisar sempre ser corrigido para que o aluno adquira

6. Como asseverei anteriormente, Bortoni-Ricardo não fez uma análise social da língua a partir do aspecto contato de línguas e Ecolinguística, não com essa nomenclatura, mas como o seu trabalho de Sociolinguística faz reflexões sobre a língua, sociedade e educação, baseio-me em seus estudos para considerar que esses fatos são mais um dos aspectos importantes para a visão e análise da língua como um ecossistema, seja do ponto de vista externo, seja do interno, sendo a Ecolinguística uma disciplina mais ampla e geral que a Sociolinguística, pois agrega não só o estudo da língua como fato social, mas também o estudo minucioso de partes da gramática relacionando-as entre si e ao social (Couto, 2007). 
domínio dessa tecnologia. No quesito língua escrita, Bortoni-Ricardo (2005: 267-88) defende a ideia de que o chamado erro é transgressão de um código convencionado e prescrito pela ortografia, recebendo, com isso, avaliação social, pois, conforme já expus, tais erros recebem uma carga social pejorativa. Dado que a ortografia não prevê variação, a sua aprendizagem é um processo contínuo, ou seja, cada palavra é fixada ao longo de anos ou séculos no processo de aprendizagem.

\section{Considerações finais}

O trabalho de pesquisa buscou, no meio ambiente, os dados da língua escrita em anúncios e placas populares e analisou como esses gêneros discursivos de escrita tiveram forte apoio nas regras fonológicas da fala. Demonstramos que vários fenômenos da modalidade oral são comuns e constantes nesses veículos de comunicação, quando inseridos em comunidades com pouco domínio das convenções ortográficas. A experiência de coletar os dados no ecossistema permitiu-nos agregar valores não só em relação à poluição visual, mas entender a língua em diversos aspectos internos e externos e relacionando-a ao meio ambiente. Assim, quando estudamos a escrita nos anúncios, não separamos o que era gramaticalmente correto do não correto, mas pudemos relacionar a língua como sistemas possíveis e interligados, o que provavelmente não seria possível se o nosso trabalho fosse focado a partir do ensino isolado de gramática não contextualizada. A ecologia dos fenômenos linguísticos oralizados foi catalogada nas propagandas e discutida amplamente em sala de aula, o que se revelou um recurso bastante útil para discussão do que seria uma língua situada em determinado espaço geográfico e o uso que o povo faz dela em determinados contextos da vida social.

Desse modo, retomando o que fora dito acima, a coleta de dados feita por alunos e professor serviu para sensibilizar os alunos quanto às questões linguísticas implicadas em sua forma de escrita, haja vista que todo o gênero discursivo eleito para a pesquisa subsidiou-nos com elementos de escrita ainda muito oralizada, o que nos permitiu perceber, 
com clareza, as hipóteses que os falantes fazem quando não dominam o código padrão. Ao fazer um trabalho de comparação a partir do que o aluno escreve e o que ele observa nas práticas sociais, a exemplo do português escrito nos anúncios populares, o exercício nos permite entender o fenômeno social da língua como um ente além da gramática tradicional, como um sistema de valores que tem suas características próprias, com implicações lógicas previsíveis e justificadas no próprio modo de constituição gramatical das línguas naturais.

O trabalho possibilitou ao educando, no ato de suas escrituras, entender porque escrevem de determinada forma e comparar com a forma eleita padronizada pela gramática, o que contribuiu para uma atitude crítica no entendimento que as regras ortográficas não necessariamente se apoiam nas regras fonético-fonológicas, e quando há dúvidas na forma de escrever, é preciso vencer as primeiras hipóteses apoiadas na fala e buscar nas fontes normativas a forma prescrita. Trabalhar nos espaços educativos da sociedade, as diferenças dialetais, os diferentes tipos de escrita padrão/não padrão como um fenômeno previsível das diferenças diatópica e diastrática no binômio fala/escrita, oralidade/letramento é, enfim, contribuir para que o falante alcance a cidadania e a inclusão social.

Recebido: 10/08/2012

Aceito: $10 / 01 / 2013$

tairj@uol.com.br

\section{Referências bibliográficas}

ABAURRE, M. B.; L. C. CAGLIARI. Textos espontâneos na primeira série (evidências da utilização pela criança, de sua percepção fonética da fala para representar e segmentar a escrita). Cadernos Cedes n. 14, 1985.

BAGNO, BAGNO. A norma oculta: língua \& poder na sociedade brasileira. São Paulo: Parábola Editorial, 2003.

BARTON, D. Literacy: an introduction to ecology of Whitten language. London: Blackwell, 1994. 
BORTONI-RICARDO, S.M. Nós cheguemu na escola, e agora? Sociolinguística \& Educação. São Paulo: Parábola, 2005.

. Educação em língua materna. A Sociolinguística na sala de aula. São Paulo: $\quad$ Parábola, 2004.

The Urbanization of Rural Dialect Speakers in Brasil. Cambridge University Press, 1985.

BRASIL. (1997). Secretaria de Educação Fundamental. Parâmetros curriculares nacionais: língua portuguesa. Brasília: MEC/SEF, vol. 2.

CAGLIARI, Luiz Carlos. Alfabetização e Linguística. São Paulo: Scipione, 1989.

. Alfabetizando sem ba, be, bi, bo, bu. São Paulo: Scipione, 1999.

CARRAHER, Terezinha Nunes. Exploração sobre o desenvolvimento da competência em ortografia em português. Psicologia, teoria pesquisa, vol.1, n 3, pp. 269-285, 1985.

COUTO, Hildo Honório do. Linguística, ecologia e ecolinguística: contato de línguas. São Paulo: Contexto, 2009.

. Ecolinguística: estudo das relações entre língua e meio ambiente. Brasília: Thesaurus, 2007. 1996. . Introdução ao estudo das línguas crioulas e pidgins. Brasília: UnB,

ERICKSON, F. Transformation and School Success: the Politics and Culture of Educational Achievement. Anthropology \& Education Quarterly, vol. 18, n. 14, 1987.

FARACO, Carlos Alberto (org). A relevância social da linguística: linguagem, teoria e ensino. São Paulo: Parábola Editorial, 2007. Escrita e alfabetização. São Paulo: Contexto, 1997.

HAUGEN, Einar. The ecology of language. In.: The ecology of language. Stanford: Stanford University Press, 1972.

LOPES, Iveuta de Abreu. Cenas de letramento sociais. Recife: Programa de Pós-Graduação em Letras da UFPE, 2006.

MARCUSCHI, Luiz Antonio. Da Fala para a Escrita: Atividades de Retextualização. São Paulo: Editora Corte, 2001.

MILROY, L.; MARGRAIN, S. Vernacular Language Loyalty and Social Network. Language In.: Society, vol. 9, pp. 43-70, 1980. 
. Language and Social Networks. Oxford: Brasil Blackwell, 1980.

MOLLICA, Maria Cecília.. Fala, letramento e inclusão social. São Paulo: Contexto, 2007.

A influência da fala na Alfabetização. $2^{\mathrm{a}}$ ed., Rio de Janeiro: Tempo Brasileiro, 1998.

PERINI, Mário A. Gramática do Português brasileiro. São Paulo: Parábola Editorial, 2010.

POSSENTI, Sírio. Por que (não) ensinar gramática na escola. Campinas, São Paulo: Mercado de Letras, 1996.

ZORZI, Jaime Luiz. A apropriação do sistema ortográfico nas 4 séries do primeiro grau. Tese de doutorado, UNICAMP, 1997.

Aprendizagem e distúrbios da linguagem escrita: questões clinicas e educacionais. Porto Alegre: Artemed, 2003. 